\title{
Designing Training Programs to Introduce Emerging Technologies to Future Workers-A Pilot Study Based on the Example of Artificial Intelligence Enhanced Robotics
}

\author{
Janika Leoste ${ }^{1, *} \mathbb{C}$, Tiia Õun ${ }^{1} \mathbb{D}$, Krista Loogma $^{1}$ and José San Martín López ${ }^{2}$ \\ 1 School of Educational Sciences, Tallinn University, 10120 Tallinn, Estonia; tiiaoun@tlu.ee (T.Õ.); \\ loogma@tlu.ee (K.L.) \\ 2 School of Computer Science \& Engineering, Universidad Rey Juan Carlos, Calle Tulipán, s/n, \\ 28933 Móstoles, Madrid, Spain; jose.sanmartin@urjc.es \\ * Correspondence: leoste@tlu.ee; Tel.: +372-504-5081
}

check for updates

Citation: Leoste, J.; Õun, T.; Loogma, K.; San Martín López, J. Designing Training Programs to Introduce Emerging Technologies to Future Workers-A Pilot Study Based on the Example of Artificial Intelligence Enhanced Robotics. Mathematics 2021, 9, 2876. https://doi.org/10.3390/ math 9222876

Academic Editors: Tomás Recio, Piedad Tolmos Rodríguez-Piñero, Ana I. Cid-Cid, Rocío Guede-Cid and Joaquín Paredes

Received: 14 October 2021 Accepted: 10 November 2021 Published: 12 November 2021

Publisher's Note: MDPI stays neutral with regard to jurisdictional claims in published maps and institutional affiliations.

Copyright: (c) 2021 by the authors. Licensee MDPI, Basel, Switzerland. This article is an open access article distributed under the terms and conditions of the Creative Commons Attribution (CC BY) license (https:// creativecommons.org/licenses/by/ $4.0 /)$.

\begin{abstract}
Implementing an Emerging Technology (ET) is a difficult task due to people lacking ETrelated knowledge and skills or having skeptical and negative attitudes towards the ET. As learners construct their understanding about an ET and develop related skills by actually passing through the ET Innovation Process (IP) stages (Awareness, Acceptance and Adoption), it could be useful to provide them with training that imitates certain IP stages. Using Artificial Intelligence Enhanced Robotics (AIER) as the example ET, we designed a two-day workshop to lead learners $(n=16)$ through the AIER IP Awareness stage, and a six-week training course with eight contact days to simulate the AIER IP Acceptance stage to learners $(n=10)$. Using online surveys and quantitative content analysis methods we confirmed that the workshop format increased the AIER-related self-confidence and general knowledge in $78 \%$ of participants, while the training course helped more than half of the participants to construct usable knowledge about a specific AIER and to see its possibilities in their specific work-place contexts. This paper is the pilot of using the Technology-Enhanced Learning Innovation Process (TELIP) model, first tested on a STEAM innovation, outside the educational context, for developing appropriate training approaches for specific ET IP stages.
\end{abstract}

Keywords: Artificial Intelligence; robotics; emerging technologies; innovation adoption; future of work; lifelong learning; training; technology skills

\section{Introduction}

The emerging technologies of the 21st century are expected to have a great impact on society [1]. Emerging Technologies (ETs) can make people's lives easier and more meaningful, but they will potentially present also several challenges that need to be addressed. One of these challenges is to equip today's workforce with the necessary skills and knowledge that would make it easier for the workers to embrace ETs. The educational system plays an important role in developing basic skills and increasing the supply of specific skills, often acquired throughout the career. The best practices and the latest technologies used at the productivity frontier generally require a more highly skilled workforce [2]. More emphasis should be given to training and lifelong learning, where substantial scope exists for possibilities to improve training uptake and quality [3]. In this paper, we examine how to design and conduct a Training Course (TC) that aims at introducing ETs to adult persons in a way that would inspire them to choose ET-related careers.

A technology is considered emerging if it is novel in a given context and its full potential would most likely be realized in the future, not in the present day. If successfully sustained, an ET can have an incremental or disruptive influence on the domain where it is used-its use can create new additional opportunities or displace already existing routines, 
methods, or tools. Rotolo, Hicks \& Martin [4] suggest that an ET is described by five key features: “(i) radical novelty, (ii) relatively fast growth, (iii) coherence, (iv) prominent impact, and $(v)$ uncertainty and ambiguity." Examples of emerging technology can include Artificial Intelligence (AI), Natural Language Processing, Robotics, Biometrics, Augmented Reality and Virtual Reality, Blockchain, 5G Broadband Cellular Networks, Internet of Things, Serverless Computing, Quantum Computing [5].

While many see ETs as promising in eliminating poverty [6] or reducing the human footprint on Earth's ecosystem [7,8], others point out that ETs could lead to an increase in inequality and growth of unemployment, and to increased concentration of income and wealth as the owners of capital could capture an ever-larger fraction of the economy, and that ETs, especially robotics and AI, could make people's jobs redundant $[9,10]$. Indeed, by $2017,31 \%$ of companies were already implementing AI and robotics in order to augment their workforce-but this did not cause a reduction in the number of jobs [11]. Instead, as implied by [12] it seems that although ETs do change the nature of work, this process results in new jobs that require people to acquire new sets of skills and knowledge. In their words, by 2030, "all workers will need to adapt, as their occupations evolve alongside increasingly capable machines". The skills they refer to, also known as 21st-century skills, are defined as a combination of cognitive, interpersonal, and intrapersonal skills that are malleable and relatively stable over time in the absence of exogenous forces [13] and include the following skills: collaboration, communication, creativity, critical thinking, problem solving, Information and Communication Technology (ICT) literacy, and social and cultural competencies [14]. These skills are critical for people to successfully adjust to the changing nature of work.

Another factor that could decrease the predisposition of the people to accept jobs that exploit ETs (i.e., to adopt the technologies that the job is based on), is their attitudes towards the ETs that are seen as responsible for changing the status quo of their work. Studies indicate that people's attitudes towards technology are connected to their willingness to adopt this technology $[15,16]$. For example, the prevalence of robotics can cause people to become afraid of becoming marginalized, form negative attitudes towards robots [17,18], and so result in people avoiding jobs that require collaboration with robotic colleagues. In addition, negative attitudes, combined with mandatory adoption, can lead to varying usage levels that may discontinue as soon as the compulsion ends [19].

The negative attitudes can be reduced and people's readiness to adopt technologies can be stimulated via several approaches, for example, by providing people with adequate information about technologies [20] or by highlighting unique human abilities that give humans a competitive edge over machines [21]. There is little literature about using approaches from the innovation studies field to provide people with adequate information about the ETs that they will potentially need to work with in the future. Adner \& Levinthal [22] imply that ETs can be considered as innovations, described in the study of technical change by [23]. As such, ETs are subject to the innovation adoption processes, outlined in various technology and innovation acceptance models, for example in the Diffusion of Innovations Theory [24], the Technology Acceptance Model [25], and others. In this paper we use the Technology-Enhanced Learning Innovation Process (TELIP) model by [26] that describes how on the end-user level, the Innovation Process (IP) of a novel technology consists of three consecutive IP stages (Figure 1): Awareness, Acceptance and Adoption (see also [24]). In the Awareness stage, the users become familiarized with the technology, its usage scenarios and its possible beneficial impact on their work-but they are not applying it directly to their workplace routines. In the Acceptance stage, the users will experiment with the technology in the context of their own needs, construct knowledge and skills that are needed to work with the technology and form their decision about the usability of the technology (i.e., are they going to continue using it?). In this stage, they still depend on outside help. The users who reach the Adoption stage, consider the technology as "need to have" for their purposes and continue improving their knowledge and skills. To ensure sustained use of the technology it is necessary to form users' positive attitudes in 
the Awareness stage and to support these attitudes by providing the necessary knowledge and forming needed skills in the Acceptance stage.

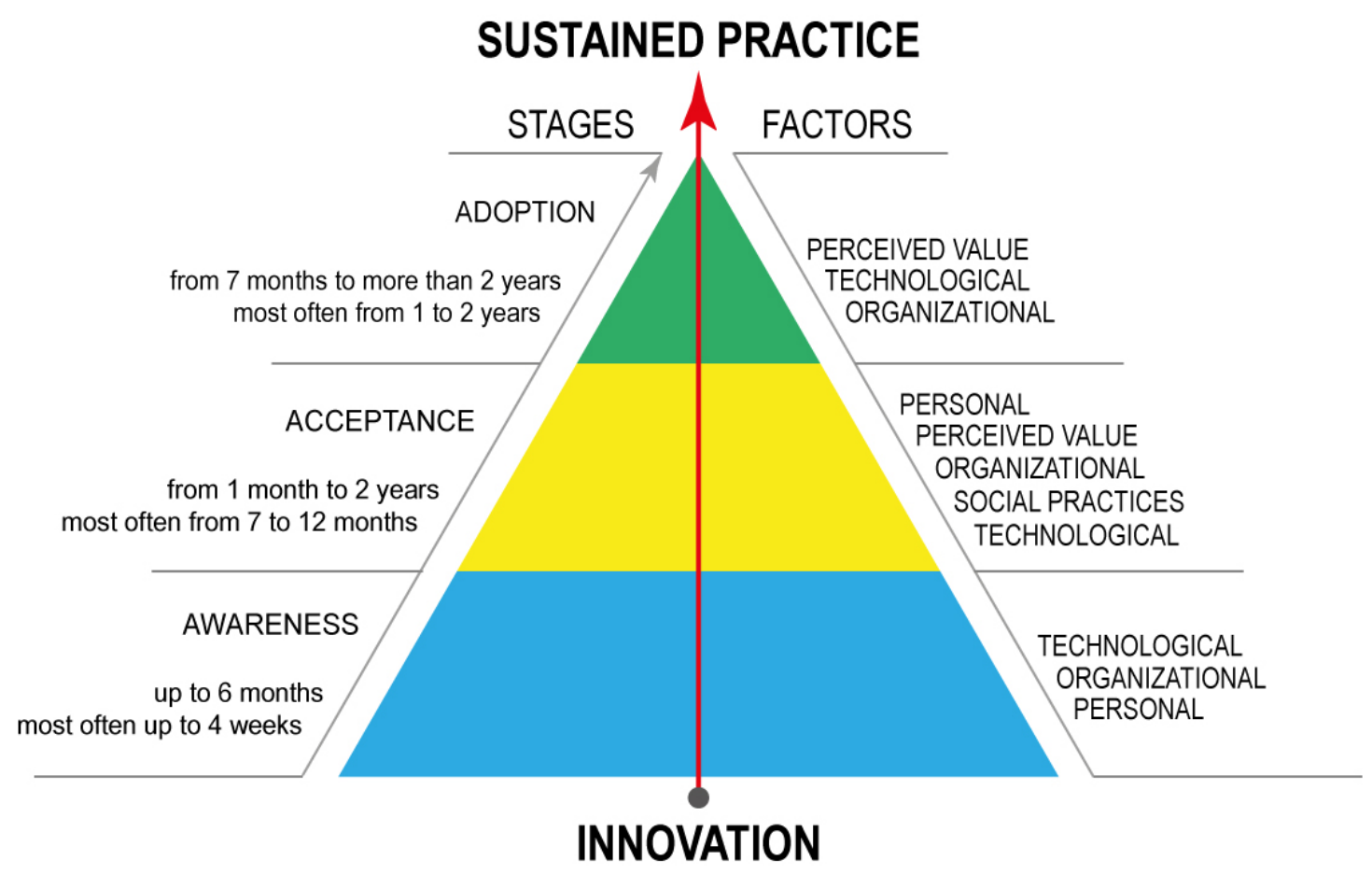

Figure 1. The IP stages and factors influencing the IP. Adapted from [26].

In a way, the Adoption stage can only take place in a real work context, the Awareness stage is "merely" a demonstration of the technology-related possibilities-while the Acceptance stage can be passed in an environment simulating a workplace. In case the users do not need to use the technology in their everyday routines in the present but might need it in the future, they need to be provided with a hands-on practical TC that simulates the stages of Awareness and Acceptance. The purpose of such a course could be proactively evoking positive attitudes and to avoid the possibility of the formation of negative attitudes towards an ET.

The TELIP model was developed as a response to the problem of STEAM (Science, Technology, Education, Art and Math) focused Technology-Enhanced Learning (TEL) innovations' sustainability in teachers' practices. Namely, many STEAM TEL innovations, despite starting with great enthusiasm will fade without leading to significant changes in educational activities $[27,28]$. The TELIP model aimed at explaining the nature of the STEAM TEL innovation process and factors that influence its outcomes. In order to develop the TELIP model, the innovation process of a certain STEAM TEL innovation, robot-supported math teaching and learning [26] was examined during a four-year study that involved 137 math teachers, 56 educational technologists, and more than 2000 students from 67 Estonian schools. Although the TELIP model was first tested during a long-term study with educational robotics in the school context, it is based on a synthesis of several well-known technology acceptance and innovation adoption models: The Diffusion of Innovations Theory by [24], The Technology Acceptance Model by [25,29], The TechnologyOrganization-Environment Framework by [30], and The Unified Theory of Acceptance and Use of Technology by [31]. This origin makes it possible to apply the model, with certain reservations, to other technological innovations in other contexts. The three-stage nature of innovation adoption at the end-user level is also described by several earlier models, e.g., [32-39]. However, the TELIP model uniquely describes IP factors that influence the outcome of IP stages, impacting thus the ability of an innovation to become sustainable. These factors are the following: technological factors, organizational factors, personal 
factors, perceived value factors and social practices' factors. The combination of active factors in each IP stage also indicates the support that is needed by the end-users during the IP stage, facilitating the planning of the innovation process.

This paper presents a pilot use of the TELIP model outside the educational context. We are going to use the TELIP model as a guiding framework for developing a possible solution for the problem of people having insecurities, or even unconscious fears towards actively seeking ET-enhanced jobs. We theorize that by the means of specially developed training courses that consider relevant IP stages it is possible to encourage people to look forward to working with ETs and to support their self-confidence about becoming "future compatible" or being able to take advantage of the choices that include the element of ETs. One of the suggestions the TELIP model offers is that people who exit an IP stage with negative attitudes towards the ET, will have difficulties in re-entering that stage or the next one, ([26], suggested also by [24]). As re-engaging these people requires more effort to convince them about the feasibility of the ET, it could be more useful to provide people with TCs that, depending on their previous knowledge and experience, imitate certain IP stages. Such a TC should allow people to exit the appropriate IP stage with positive attitudes that help them to successfully enter the next IP stage, leading to final adoption of the ET.

At this point, we propose that for leading people into and through the ET IP Awareness stage it is appropriate to use the workshop format-a short training course with a duration of two days. A workshop is often used as a learning method to evoke systematic changes in people's attitudes and behaviors. During a workshop, active learning is encouraged through a short-term learning experience [40]. Active learning is suitable for developing adaptability, creativity, curiosity and open-mindedness [41]—characteristics that help people to become interested in the subject learned. In a typical workshop, learners are actively engaged with their peers and their teachers. The format of a workshop as a onetime event could be suitable for creating awareness about a certain ET (i.e., to lead people to and through the Awareness stage). We also suggest that convincing people to choose for ET-related careers (i.e., to enter and pass the Acceptance stage) might require a longer-term TC. The purpose of such a TC would be to provide people with a combination of theoretical knowledge and practical experience, in order to form positive future expectations about the studied ET. The duration of this TC should be at least the same as the minimum duration of the Acceptance stage, described by the TELIP model, and it should simulate at an accelerated pace, the processes that would normally take place at the workplace. In order to facilitate people to rapidly assimilate new knowledge and develop new skills, the TC should provide them with a theoretical background from university researchers and practical know-how from a support person of industry.

Collaboration between university and industry is critical in curriculum development, in order to prepare learners for real-world conditions [42]. An industry partner can help make the curriculum relevant to industry expectations and provide learners with professional expertise, giving thus credibility to the curriculum [42,43]. University-industry collaboration can help ensure that learners are provided with employability skills that increase the individual's ability to secure and be successful in a job of their choice, making them thus more employable [44,45]. In the context of this paper, university-industry collaboration allows for the integration of the university researchers' theoretical knowledge about ETs with the industry experts' practical know-how.

The main goal of the paper is to design and validate two different training formats that, in the university-industry partnership, utilize the unique knowledge and experience of the university researchers and industry experts, in order to lead learners through the ET IP Awareness and Acceptance stages. The study design makes use of two research phases, built on each other: (a) in the first phase (Phase 1) a two-day workshop is conducted with the goal of increasing university students' understanding about a certain ET, Artificial Intelligence Enhanced Robotics (AIER), using the example of two educational AI-enhanced 
robots; and (b) in the second phase (Phase 2), based on the data from Phase 1, an eight-day TC is designed and conducted, using the UR3e robotic arm as an example of AIER.

In both of the phases the knowledge from two professional communities-university researchers and industry experts-is synthesized with the aim of encouraging learners to experiment with AIER devices and with new methods that are needed for constructing a basic understanding and positive attitudes towards AIER. University members (innovation and robotics researchers; adult learning didactics; sustainable development experts; philosophy professors) were playing an active role in the process of constructing participants' understanding and attitudes, by providing the methodological, didactical and technological expertise. Industry experts were supporting the study with their specific knowledge about the everyday practical aspects of using AIER devices. Based on the notions above, we have formed the following Research Questions (RQs) to guide our study phases:

Phase 1 (Section 3) is guided by RQ1: Is workshop an appropriate training format for leading people to and through the AIER innovation process Awareness stage in a way that ensures learners' positive future expectations towards AIER?

Phase 2 (Section 4) is guided by RQ2: Is training course an appropriate training format for leading people to and through the AIER innovation process Acceptance stage in a way that prepares learners to accept AIER-enhanced jobs?

\section{Materials}

\subsection{AI-Enhanced Robotics}

$\mathrm{AI}$ is a combination of hardware and software (algorithms) that allows a machine to exhibit an intelligent behavior, i.e., to exploit an animal-like intelligence. Modern AI is often able to reason, build knowledge, plan, learn (including human language) and perceive. In recent decades, some AI solutions have been able to perform complex movements and manipulate objects, similarly to humans.

AI could potentially allow machines to exhibit features similar to humans-for example, manipulate information (remember, reason, plan or learn), use human language for communication, perceive, make complex movements and manipulate objects, fuzzy behaviors and decisions. The combination of $\mathrm{AI}$ and robotics make it possible to exploit the approach of Embodied Cognition (EC), an idea that for higher intelligence, some aspects of the body, especially perception and movement, are needed [46]. The advances of both AI and robotics have made it possible to meaningfully combine AI with robotics. On the one hand, this provides AI with input systems (touch, sight, and hearing) and output systems (moving limbs, communication) of a robotic body. On the other hand, advanced AI allows a robotic body to exhibit complex movements and behaviors, similar to biological bodies. An example of anthropomorphic or zoomorphic robots that employ AI for their movement and behavior, is the Boston Dynamics' Atlas robot that is able to conduct complex human movements, such as parkour [47]. With their human-like properties, AIER is often perceived as a threat to human existence $[17,18,48]$, or at least capable to infiltrate human society, changing remarkably the ways work is done or how people communicate with machines and each other [49-51]. As AIER is also one of the ETs that most people are aware of, it is a suitable testing ground for approaches that provide people with the necessary knowledge for their future lives.

\subsection{ClearBot and Poppy Ergo Jr}

ClearBot, and Poppy Ergo Jr (Figure 2) are educational robots that are suitable for familiarizing learners with the concepts of robotics and AI. 


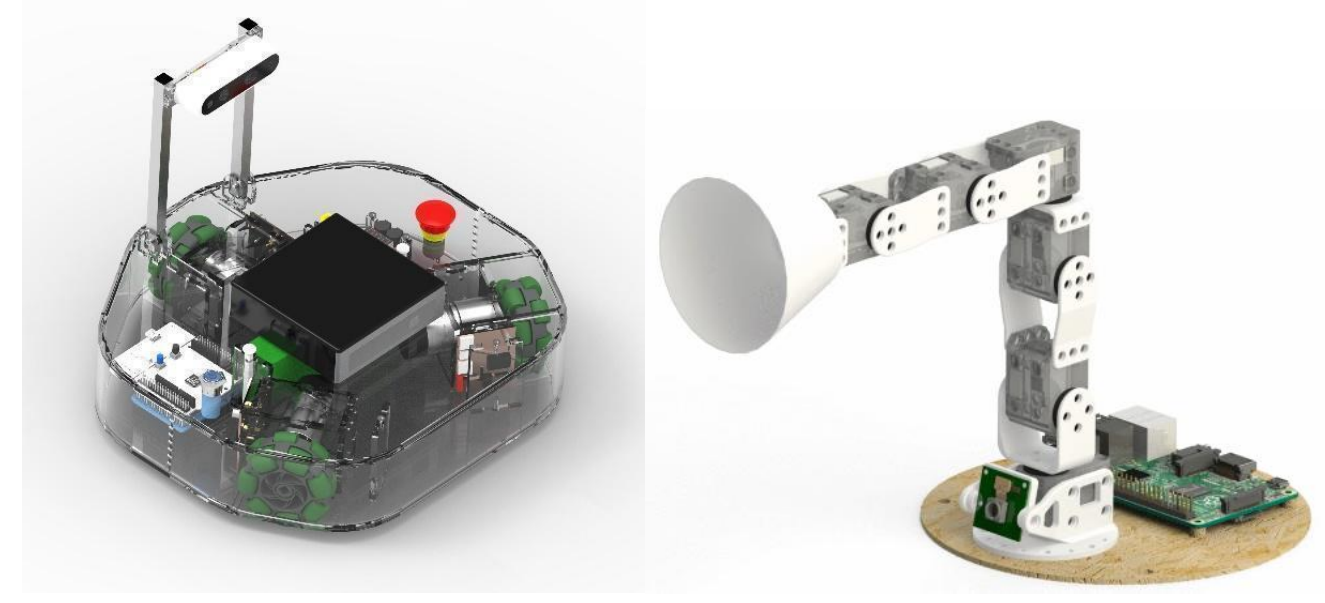

Figure 2. ClearBot (left) and Poppy Ergo Jr (right).

ClearBot (https: / / clearbot.eu/technology/, accessed 11 November 2021) (Figure 2, left) is an education robot with dimensions about $30 \times 30 \times 30 \mathrm{~cm}$. The exact dimensions depend on the particular hardware configuration. The educational aim of ClearBot is teaching computer vision, machine learning, and wheeled mobile robotics. ClearBot has relatively high-end hardware, as its CPU is 7th generation Intel Core i5 and its GPU is Intel Iris Plus Graphics 640. ClearBot uses Intel Realsense D435 3D Depth camera for computer vision, and three separately controlled omnidirectional wheels for movement. ClearBot can be programmed by using Robot Operating System (ROS).

Poppy Ergo Jr (https: / / www.poppy-project.org/en/robots/poppy-ergo-jr/, accessed on 11 November 2021) (Figure 2, right) is a relatively small educational robotic arm that can be built with 3D printed components. Its educational aim is to teach programming, robotics, engineering, design and geometry in the classroom environment. Poppy Ergo Jr is based on six servomotors that are controlled by the Raspberry Pi minicomputer. Poppy Ergo Jr can be programmed via ROS, Python, or via Snap (a visual programming language, similar to Scratch).

\subsection{UR3e Collaborative Robot}

The UR3e collaborative robotic arm (https:/ / www.universal-robots.com/products / ur3-robot/, accessed on 11 November 2021) (Figure 3) is a relatively small, flexible and lightweight collaborative robot that can work side-by-side with people. It weighs $11.2 \mathrm{~kg}$, it is able to manipulate objects weighing $3 \mathrm{~kg}$, its footprint is $\varnothing 128 \mathrm{~mm}$, and its reach is $500 \mathrm{~mm}$. All the UR3e's wrist joints have 360-degree rotation freedom, its end joint has infinite rotation freedom. The tasks UR3e can perform include assembly, polishing, gluing \& dispensing, screw driving, pick \& place, lab analysis and testing, and inspection. UR3e can be used in various industries where uniform product quality is required, such as pharmaceuticals, electronics, food and beverages, cosmetics, and chemicals [52].

UR3e is easily programmable via its 12 " touchscreen with the Polyscope graphical user interface that requires no previous programming experience to operate. Easy programming allows to re-purpose the robot as the manufacturing needs change, reducing the total cost of ownership. 


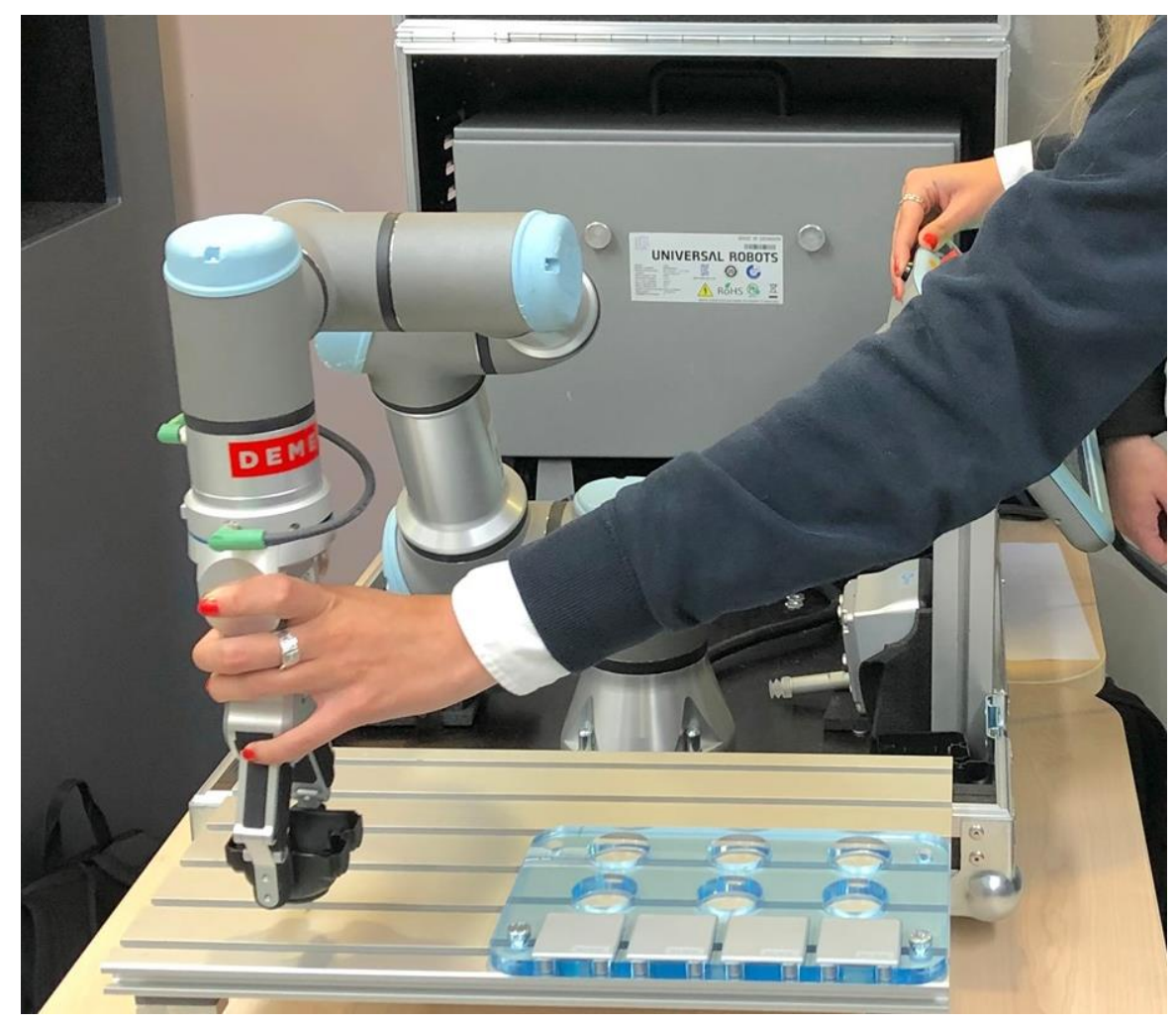

Figure 3. UR3e Collaborative Robot.

\section{Phase 1: Workshop "My Future Colleague Robot"}

The goal of Phase 1 was to bring learners that had no previous experience with AIER to the AIER IP Awareness stage, meaning that they would become aware of the technology, construct a basic understanding of its opportunities and challenges, acquire elementary AIER-related skills, and would be ready to move on to the Acceptance stage if required by their future career choices. According to the TELIP model, the natural duration of the Awareness stage can be rather short, starting from only a couple of days [26]. We used the workshop learning-teaching format, as it matches these requirements: it can provide a basic understanding of the technology, allows a hands-on approach for developing basic skills, and has a potential duration of a few days.

\subsection{Method}

\subsubsection{Description and Implementation}

We designed a two-day experience workshop with the goal of introducing AIER, based on the example of the educational robots Poppy Ergo Jr and Clearbot, to university students, and encouraging them to form positive attitudes towards AIER. The workshop took place in February 2021. The workshop's concept is graphically illustrated in Figure 4.

The workshop's first day consisted of four main sessions: (a) a short overview of robotics, AI, and studies about people's attitudes towards robots; (b) a demonstration of the Poppy Ergo Jr robot and its capabilities; (c) a hands-on session for the participants to experiment with the Poppy Ergo Jr robot, and (d) a more thorough overview about the Poppy Ergo Jr robot. The sessions (a), (b) and (c) were conducted by university researchers, and session (d) was conducted by the developers of the Poppy Ergo Jr robot. 

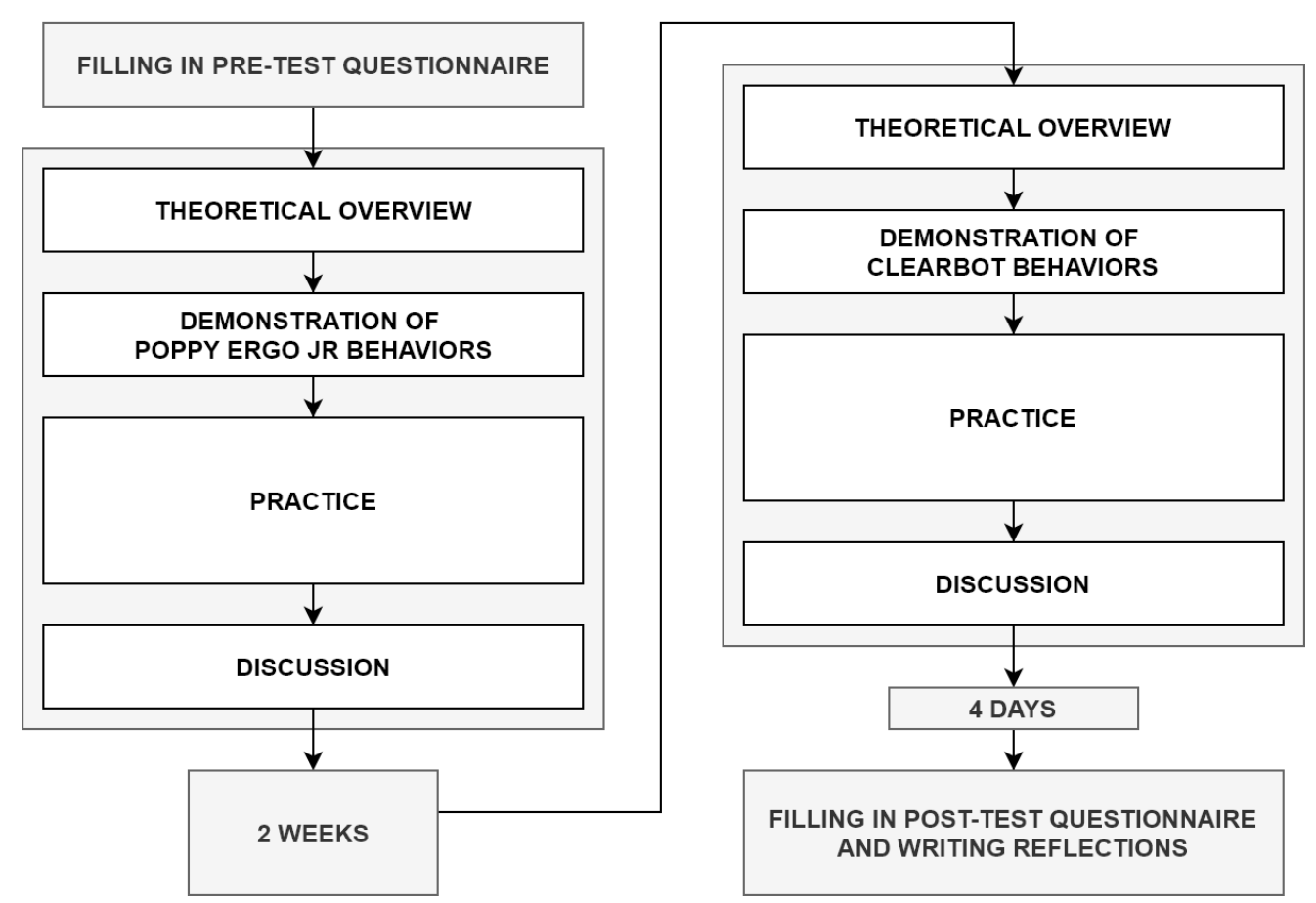

Figure 4. The structure of the "My Future Colleague Robot" workshop [53].

The workshop's second day took place two weeks after the first one and had a similar structure: (a) a short overview about the robotics-related global challenges, influence on environment and society; (b) a demonstration of the Clearbot robot and its capabilities; (c) a hands-on session for the participants to experiment with the Clearbot robot, and (d) a more thorough overview about the Clearbot robot. Similarly to the first day, the sessions (a), (b) and (c) were conducted by university researchers, and session (d) was conducted by the developers of the Clearbot robot.

\subsubsection{Data Collection and Analysis}

Before and after the workshop we asked the workshop participants to argue in free form text how they see robots in their personal and work lives after 10 years from now on. For this we used an online survey with two sets of questions:

1. Please describe what role, in your opinion, the intelligent robots will play at your workplace after 10 years. Do you see them as friends, colleagues or tools?

2. Please describe what role, in your opinion, the intelligent robots will play in your personal life after 10 years. Do you see them as family members, friends, slaves or tools?

We used the quantitative content analysis method with closed coding [54] to analyze the submitted information. The closed codes used for coding were the following: robots perceived as (a) tools; (b) colleagues; (c) friends; (d) advanced tools; (e) servants; and (f) family members. In addition, the participants were asked to give post-workshop feedback as an essay via email about their previous contact with AIER, the workshop content, its influence on themselves, and to share their thoughts about improving the workshop so it would be more useful in introducing AIER to different target groups. We used interpretative phenomenological analysis [55] to analyze the content of the essays. Two general categories were generated first: (a) a participant's previous experience with AIER and (b) a participant's self-observed improvement of their skills, knowledge, selfconfidence and interest. Based on these categories we made an initial review of the essays and developed codes for each category. Next, we analyzed the essays again, and marked the presence of codes in the texts, counting each code once per participant's essay. 
The data coding was conducted by two researchers in order to account for personal biases that could have had an impact on findings [56]. In the interests of coding reliability, the researchers agreed on the inclusion criteria before the coding process and solved discrepancies after coding through discussion [57]. The coding followed the guidelines given for situations where calculating inter-rater reliability is not desirable [57].

\subsubsection{Sample}

The workshop participants were 16 university students of masters and bachelor's degree level (nine male and seven female, 20 to 50 years old with an average age of 33), from the fields of social sciences, educational sciences and computer sciences. Of these participants, 16 persons filled in the online query about the AIER's possible future roles, and nine persons submitted their feedback essays for the workshop $(n=9)$.

\subsection{Results}

Our first research question was "Is workshop an appropriate training format for leading people to and through the AIER innovation process Awareness stage in a way that ensures learners' positive future expectations towards AIER?" To answer this question we examined the participants' responses to the online survey and their essays.

The responses to the online survey questions were analyzed in order to find out how the workshop influenced the participants' perception of AIER (Table 1). At the workplace, the AIER was perceived relatively neutrally: as tools (62\% of answers, $18 \%$ increase), colleagues (54\%, 9\% decrease); friends (38\%, 7\% increase). At homes, the robots were considered useful as (advanced) tools (92\%, 4\% increase), servants (38\%, 13\% increase), and friends $(23 \%, 2 \%$ decrease). There were no participants who would consider AIER as their family members. These numbers allow us to suggest that the workshop improved the participant's understanding of AIER.

Table 1. Learners' attitudes towards robots. The Delta column represents the deviation from the pre-workshop values.

\begin{tabular}{|c|c|c|}
\hline Code & Expressed by Percentage of Learners & Delta \\
\hline \multicolumn{3}{|l|}{ At workplace } \\
\hline Tools & $62 \%$ & $18 \%$ \\
\hline Colleagues & $54 \%$ & $-9 \%$ \\
\hline Friends & $38 \%$ & $7 \%$ \\
\hline \multicolumn{3}{|l|}{ At home } \\
\hline Tools & $92 \%$ & $4 \%$ \\
\hline Servants & $38 \%$ & $13 \%$ \\
\hline Friends & $23 \%$ & $2 \%$ \\
\hline
\end{tabular}

The content of the essays revealed the following information (Table 2). Most of the participants had no previous meaningful contact with AIER. For 56\% this was their very first contact with this ET (e.g., "At the very first meeting, I felt a little awkward, because although I am interested in any field of IT, etc., my knowledge is still quite poor."), while $11 \%$ of them $(\mathrm{n}=1)$ had some previous experience (e.g., "I've been in contact with learning robots a bit before, but I saw and tried such a robot hand for the first time."). The growth of self-confidence as a result of the workshop was noticed by $78 \%$ of the participants (e.g., "The workshop was actually very cool. I liked that we could actually experiment with Poppy, and I got the reassurance that you don't have to be a certified engineer to perform such simpler functions."). 78\% of the participants also observed the growth of their understanding about AIER (e.g., "Everything was clear. Personally, I had thoughts about what could be done with this robot, that is, the feeling that a robot like this robot would allow me to do more vital things in the future."). 33\% of the participants became inspired to learn more about AIER, and also 33\% of the participants contemplated about the possibilities of using this ET by themselves. 
Table 2. Presence of AIER related codes in participants' essays.

\begin{tabular}{lc}
\hline \multicolumn{1}{c}{ Code } & Presence in the Participants' Essays \\
\hline Had previous experience with AIER & $11 \%$ \\
This was the first contact with AIER & $56 \%$ \\
Self-observed growth self-confidence related to & $78 \%$ \\
AIER & \\
Self-observed growth of knowledge about & $78 \%$ \\
AIER & $33 \%$ \\
Got new ideas on how to use AIER & $33 \%$ \\
Became interested in learning more about AIER & \\
\hline
\end{tabular}

\subsection{Discussion}

The feedback from the participants suggests that the workshop helped them to improve their understanding of AIER and cultivated rational and realistic attitudes towards this ET. The workshop format, if properly conducted, creates interest in AIER and desire to further experiment with it-but does not influence everyone in the same way. In our investigation, only a third of the learners were interested in learning more about AIER-a reasonable share, considering that most of our participants were from the humanitarian areas. However, a great majority of the participants became more self-confident and knowledgeable about AIER, indicating that the workshop had been successful in creating positive awareness about AIER.

In conclusion, these developments indicate that the workshop format we developed could be considered, after further improvements, to be suitable for bringing a learner to the ET IP Awareness stage. A properly prepared and conducted workshop can ensure learners' positive attitudes towards AIER and help them to become self-confident about their skills and knowledge, related to the ET. However, it is only in the Acceptance stage where the learners shape their conviction about their abilities to really use technology in their daily work routines. So while the workshop format could give some initial enthusiasm and understanding of the overall features of the technology, more is needed for preparing people to accept ET-enhanced jobs. It is the Acceptance stage where the learners make a personal decision about the usability of a technology in their job routines. In order to encourage learners, including this $67 \%$ of the learners in the workshop who were not interested in further experimenting with AIER, to start considering AIER-related future careers, we consider it necessary to guide them through the simulated Acceptance stage. For this, it is necessary to give people self-confidence in their ability to cope with technology when the situation calls for it (see also [58]). However, due to its short duration, the workshop format is not able to provide enough hands-on time for experimenting with the devices and constructing a comprehensive understanding of the technology. In addition, in the Acceptance stage learners need to be provided with a suitable framework that allows them to coherently organize their newly constructed knowledge, in order to make it usable. This framework includes knowledge about the technology and aspects related to it, about the possible usage contexts, but also about the proper methods of learning this technology.

\section{Phase 2: Training Course "My Future Colleague Robot"}

The results of Phase 1 gave valuable input for designing a full-length TC for adult learners. We concluded that for various reasons the workshop format could be inadequate when the goal is to guide learners through the Innovation Stage Acceptance stage-mostly because its duration is too short to develop realistic skills for using a complex ET, such as AIER. The TELIP model suggests that depending on the complexity of a technology, its IP Acceptance stage can last from a month to a couple of years in real-life settings [26]. We propose that it is possible to use an intensive TC to adequately simulate the Acceptance stage during a much shorter time. Therefore, the goal of Phase 2 is to establish whether a full-length TC could be used to guide learners through the IP Acceptance stage. 
There are indications that the transition of learners from the Awareness stage to the Acceptance stage requires the learners to become convinced about the usability of technology in real-life situations ([59,60], as also noted by [24]). However, in the Acceptance stage, the learners develop their opinion about the usability of the technology in their own particular everyday routines. So while the task of the Awareness stage is to encourage learners to start experimenting with a technology, the task of the Acceptance stage is to incline learners to accept the technology as one of their regular work tools. In the Acceptance stage, the learners use the technology regularly in their work routines, although they have not yet developed proper usage methods, lack knowledge and skills to efficiently exploit the opportunities that the technology offers, and often need a support person to help them [60]. These notions indicate that TC that simulates the Acceptance stage should include as much as possible real-life hands-on experience, constant support-even for the independent work, but also additional information that helps learners to construct an adequate point of view on the technology.

\subsection{Method}

\subsubsection{Training Course Description and Implementation}

A full-length TC was designed with the goal of introducing AIER (based on the example of the collaborative robotic arm UR3e) to persons active in the labor market, to help them to develop the basic set of skills needed to operate this robot and to encourage them to form positive attitudes towards AIER and jobs that include such ETs. One of the particular goals is to help participants to reach the level of self-confidence that would make it easier for them to accept future jobs, enhanced by AIER, and prepare them for job interviews where employers seek to confirm skills instead of checking credentials [61].

The TC was divided into eight contact days (five academic hours per day, $40 \mathrm{~h}$ total) that were dispersed over 6 weeks (Figures 5 and 6). This iterative nature should lead to the accumulation of the participants' knowledge, improvement of their skills, and shaping their positive attitudes towards AIER. The duration of the course considers the TELIP model (Figure 1) offered by [26]) and is sufficient for the participants to pass the AIER IP stages of Awareness and Acceptance and to become prepared to enter the Adoption stage if offered an AIER-enhanced job.

The TC was implemented in the spring of 2021 when it was offered as a regular adult distance training program (worth 2 ECTS credit points) jointly by the Tallinn University's School of Educational Sciences and a limited liability company Demek CNC.

The contact days were conducted as distance learning sessions via the Zoom videoconferencing software. In addition, the participants were allowed to schedule individual in-person meetings in order to get hands-on experience with the UR3e robotic arm. The typical contact day consisted of the following sessions: (a) coaching about adult learning; (b) general information about robotics and AI; (c) general information about the influence of robots on society, environment and sustainable development; (d) demonstration of the UR3e robotic arm; (e) information about using and learning specific types of robots, their use scenarios, usage safety, etc.; (f) teamwork on developing potential usage scenarios in participant's current and future jobs, and (g) sharing and discussing teamwork results, joint construction of understanding about the topics of the contact day. The sessions (a), (b) and (c) were conducted by the university researchers; the sessions (d) and (e) were conducted by the industry experts, and sessions (f) and (g) were guided by the university researchers. The contact days were followed by the periods when the participants designed independently (in total 12 estimated academic hours) possible usage scenarios for AIER and related processes and developed further their knowledge and skills by using an online simulation environment eSeries Core Track (https: / / academy.universal-robots.com/freee-learning/e-series-e-learning/e-series-core-track/, accessed on 11 November 2021). 


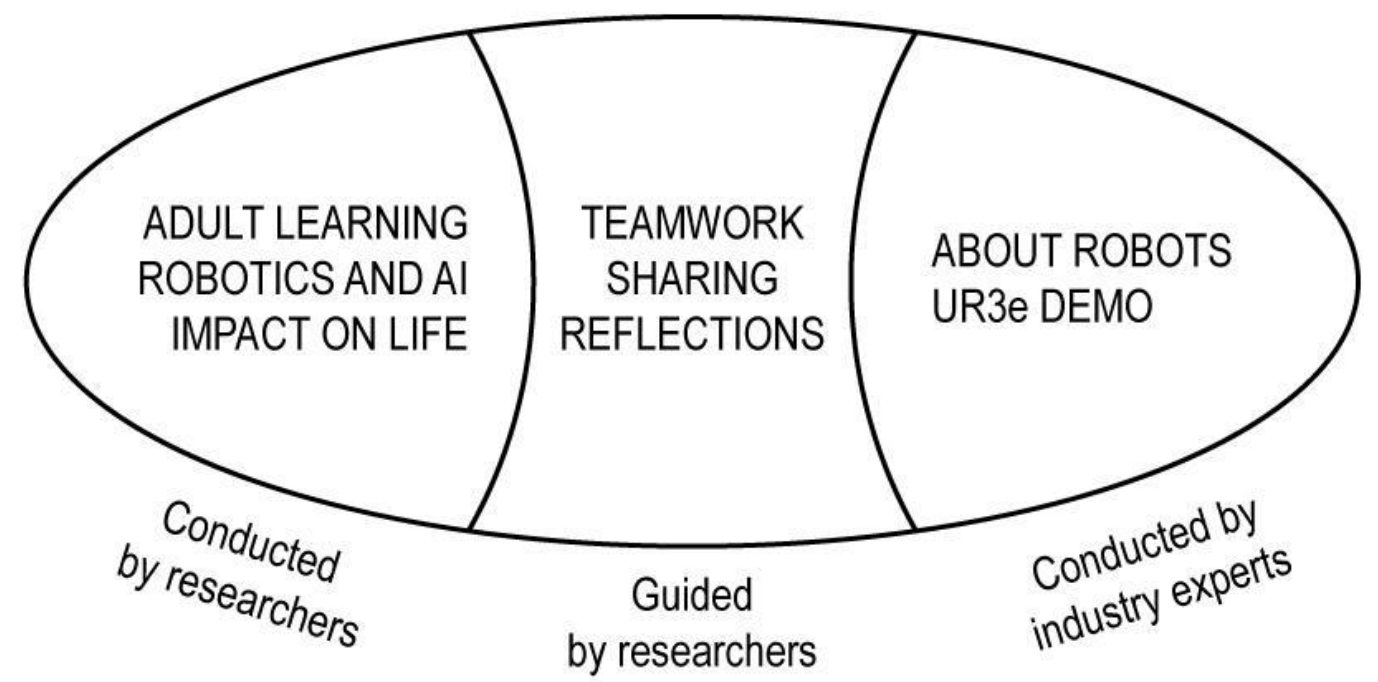

THEORY

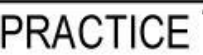

Figure 5. Training course modules.

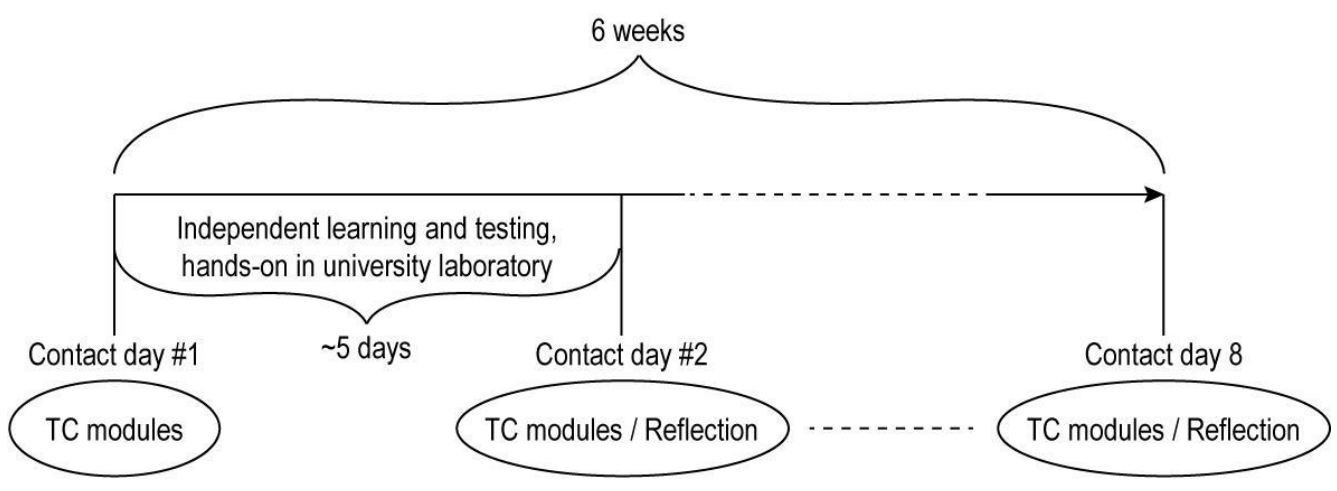

Figure 6. Training course timeline.

Compared to the measures we conducted with the workshop, we now focused on greater detail on certain aspects of the TC. For example, due to the facts that (a) the participants were employed adults; (b) the taught AIER was a real industrial robotic arm; and (c) the TC aimed at developing knowledge and skills needed at actual workplace situations, the participants were asked to evaluate skills and knowledge about this ET and about the UR3e robotic arm. In addition, we were interested in getting a better overview of the effectiveness of the training components.

\subsubsection{Data Collection and Analysis}

We used an online survey with four closed questions with 6-point Likert scales and a multiple-choice question, to gather data about participants' attitudes towards TC, AIER, and their future outlooks about using this ET in their current and future workplace. The questions were the following:

A. Items about the participant's feedback on the training course performance, with Likert rating scale from 1 (strongly disagree) to 6 (strongly agree):

- Did the training content match your expectations?

- Please rate how much do you know about using the UR3e robotic arm?

- Please rate how much are you able to offer suggestions for using the UR3e robotic arm in your work?

- How much can you use learned skills in your daily work/activities? 
B. Multiple-choice item about the participant's feedback on the training course topics:

- Please evaluate, which training course topics were the most needed and interesting for you?

Introduction of the world of robotics

The role of robots in shaping a sustainable world

Ethics aspects of using robots

Demonstrations of the UR3e collaborative robotic arm

- Work safety with collaborative robots

The data processing and analysis were conducted jointly by two researchers in order to preclude possible data handling errors and to account for possible personal biases [56]. The participant's answer was considered positive if its rating value was higher than 3 (out of 6).

\subsubsection{Sample}

The TC targeted small-office and home-office employees, non-profit organizations and unemployed persons. Of the 17 participants, 14 were employed, two were unemployed and one was a university student; 13 participants were male, four were female. The age of the participants was not recorded. The participants were guided by four university trainers (experts of educational robotics, adult learning and sustainable development) and 3 industry experts. The surveys were filled in by 10 participants, of these seven were employed, two were unemployed and one was a university student. Half of these persons were looking for a job or for a new professional challenge.

\subsection{Results}

Our second RQ was: "Is training course an appropriate training format for leading people to and through the AIER innovation process Acceptance stage in a way that prepares learners to accept AIER-enhanced jobs?"

While $70 \%$ of participants received the TC positively (e.g., "The training was very instructive, when considering the future"), the rest of the results leave room for discussion (Table 3). More than half of the participants managed to construct usable knowledge about the UR3e robotic arm and became able to offer suggestions for using the robotic arm in their work (e.g., "25+ years of experience in industrial automation, as a physicist I can usually offer something practical"), and about half of the participants considered their knowledge about the robotic arm as adequate (e.g., "On a daily basis, I work largely with the industrial sector, as well as with other companies in the field, where robotization is extremely important. Knowledge about the robot-hand's logic allows me to have longer dialogues."). In addition, $30 \%$ of the participants were able to connect what they learned with their current work or activities (e.g., "I made the final assessment already for my everyday work."), while $60 \%$ were doubtful about it (the rating value was 3 out of 6).

We also examined, which TC modules were considered necessary by the participants (Table 4). Of the modules that the participants valued the most $(80 \%)$ "The role of robots in shaping a sustainable world" explained the impact of robotics on human society and the environment and described related challenges. Additionally, the modules "Demonstrations of the UR3e collaborative robotic arm" (70\%) and "Introduction of the world of robotics" (50\%) were considered necessary. It is interesting to note that for the participants the modules about work safety and ethical aspects of using robots were not considered as important (respectively $30 \%$ and $40 \%$ of the learners). 
Table 3. Learners' evaluation of the training course performance, rating-scale items.

\begin{tabular}{|c|c|c|c|c|c|c|c|}
\hline \multirow[t]{2}{*}{ Rating Scale Item } & \multirow{2}{*}{$\begin{array}{c}\text { Average } \\
\text { Rating }\end{array}$} & \multicolumn{6}{|c|}{$\begin{array}{l}\text { Percentage of Learners } \\
\text { Per Rating Point }\end{array}$} \\
\hline & & 1 & 2 & 3 & 4 & 5 & 6 \\
\hline Did the training content match your expectations? & 4.2 & - & - & $30 \%$ & $30 \%$ & $30 \%$ & $10 \%$ \\
\hline $\begin{array}{l}\text { Please rate how much do you know about using the UR3e } \\
\text { robotic arm? }\end{array}$ & 3.4 & $10 \%$ & - & $40 \%$ & $40 \%$ & $10 \%$ & - \\
\hline $\begin{array}{l}\text { Please rate how much are you able to offer suggestions for } \\
\text { using the UR3e robotic arm in your work? }\end{array}$ & 3.8 & $10 \%$ & - & $30 \%$ & $30 \%$ & $20 \%$ & $10 \%$ \\
\hline $\begin{array}{l}\text { How much can you use what you learned in your daily work } \\
\text { and activities? }\end{array}$ & 3.3 & - & $10 \%$ & $60 \%$ & $20 \%$ & $10 \%$ & - \\
\hline
\end{tabular}

Table 4. Learners' evaluation of the training course performance, multiple-choice item.

\begin{tabular}{lc}
\hline \multicolumn{1}{c}{ Item } & Percentage of Learners \\
\hline Please evaluate, which training course topics were the most needed and interesting for you? \\
Introduction of the world of robotics & $50 \%$ \\
The role of robots in shaping a sustainable world & $80 \%$ \\
Ethics aspects of using robots & $40 \%$ \\
Demonstrations of the UR3e collaborative robotic arm & $70 \%$ \\
Work safety with collaborative robots & $30 \%$ \\
\hline
\end{tabular}

\subsection{Discussion}

The experience and feedback from designing and conducting an AIER workshop (Phase 1) helped us to design a TC (Phase 2) that largely met the participants' expectations (average rating value 4.2 out of 6 ) and helped more than half of the participants to acquire necessary skills and knowledge to operate the UR3e robotic arm. However, it is more difficult to assess whether the TC fulfilled the goal of guiding learners through the AIER IP Acceptance stage in a way that they would be ready to move instantly to the Adoption stage in their next job - or if the TC encouraged them to start looking for AIER-enhanced jobs. Our previous experience [60] indicates that the transition from the Acceptance stage to the Adoption stage happens when learners become convinced about the overall positive effects of the technology on the outcomes of their work. In addition, learners need to build sufficient self-confidence in their skills and knowledge that are needed to use the technology-in order to become able to independently work with the technology and further develop their technology-related skills and knowledge.

The results of Phase 2 indicate that half of the learners developed skills and knowledge to use AIER independently and became convinced about their ability to offer recommendations for using AIER in their workplace environment. At the same time, the gathered data also indicates that not all of the learners were able to further develop their newly acquired skills and knowledge at their present workplace, meaning that these would fade in time [62], while, hopefully, the acquired self-confidence will encourage the learners (see also [58]) to overcome their insecurities and consider accepting jobs with AIER involvement. In addition, we need to study why the need for some of the modules, such as ethics and workplace safety, was rather low. One of the reasons could be in the fact that most of the participants were already working in technical jobs where they could have already received similar training and had, therefore, no further need for these modules-but we need to clarify if there are also other reasons.

The TC was originally planned as an in-person TC. Due to the restrictions of the COVID-19 era, we chose the distance model very early, without a clear understanding of the ramifications of this choice. This could have influenced the TC results negatively, despite the possibility of independently experimenting in-person with AIER, and of the 
availability of well-developed simulation tools, such as the eSeries Core Track software that we used. We also need to study if the low scores (rating value $<3$ ) from a few individuals could have been caused by the lack of previous general technical experience, by using the distance learning approach, or by something else that did not allow us to properly address the interests of the specific learner group.

\section{Conclusions}

The 21st century is characterized by the rapidly changing meaning of the nature of work. Low-skilled jobs are being wiped out and advantage is given to the people with good skills in ETs. Literature indicates that virtually all CEOs tend to believe that ETs will have a disruptive impact on their companies and most of them find their organizations lacking skills to adapt [62]. Studies have shown that there is a significant positive link between higher skill levels and productivity [63]. The demand for skilled workers is growing, with employers globally struggling to find workers with the right mix of technical skills and human capabilities [64] and leading to a situation where "for the first time in a generation, workers are gaining the upper hand" [65]. This upper hand makes it easier for workers to become employed but on the other hand, it points at an urgent need for retraining people, to adapt to the emergence of new technology, new jobs, and even new language, amplified by the fact that the half-life of skills is falling rapidly [64]. These requirements pressure workers to become flexible and curious, with a positive outlook on lifelong learning, as these characteristics enable them to continuously learn new skills in order to retain their position in the labor market [3]. The problem of retraining people to adopt ETs is felt on the level of business organizations where many modernization attempts fail, as innovation process planners do not possess models that would provide a clear understanding of how to achieve adoption goals-resulting in progression from one ET IP stage to another becoming almost uncertain [66].

The purpose of our study was to contribute to this gap in the job market of needing more people with skills and knowledge about ETs by offering training approaches that take into account the three-stage nature (Awareness $\rightarrow$ Acceptance $\rightarrow$ Adoption) of the ET innovation adoption process. The time-dependent nature of the end-user needs during the IP stages is pointed out by [35] who recommend providing people with adequate information during the different IP stages, using different approaches. In addition, [67] confirms that adoption outlooks improve when the adopters are timely supported with appropriate information by (in the case of Brazilian agriculture) their younger, more digitally literate peers during the IP stages that correspond to the TELIP model's Awareness and Acceptance stage.

We chose AIER as an example of ETs and proposed and developed two different approaches that were designed to introduce AIER to people of different previous backgrounds with the aim of providing them with necessary skills, knowledge and positive attitudes that would encourage them to accept and seek AIER-enhanced jobs.

First, we focused on the workshop approach, assuming that the workshop format is more appropriate for people with minimal previous knowledge about AIER. The aim of such a workshop would be to guide people to and through the IP Awareness stage, providing them with some basic skills to work with AIER, and a general understanding of AIER and opportunities and problem areas related to it. This approach is also supported by [67] by suggesting that workshops and other short networking events during the Knowledge stage (corresponds to the TELIP's Awareness stage) greatly influence the technology adoption rates.

Our results confirmed that workshops can be used for introducing AIER as in our case the learners became more interested in AIER and developed realistic positive attitudes towards it. This confirms the observations by [39], who described the creation of end-user awareness about the technology and its abilities during the IP Awareness stage (corresponds to the TELIP's Awareness stage). However, due to their limited format, workshops might not be suitable for training people who need to construct a more thorough and systematic 
understanding of an ET and develop skills needed for using this ET, especially if more complex technologies are considered.

Based on the feedback from the workshop approach we developed a TC with the purpose of providing learners with a realistic functional environment for them to construct a usable framework of knowledge and skills for using a certain AIER - the UR3e robotic arm. Our goal was to simulate workplace use of the robotic arm in a way that would support the learners to pass the IP Acceptance stage, helping them to become convinced about the feasibility of AIER and about their ability to use AIER in a real-life workplace. Our results prove that the TC approach, described in Phase 2, is suitable for many adult learners. The authors of [39] similarly highlight the need to provide end-users during the Consideration stage (corresponds to the TELIP's Acceptance stage), with more detailed knowledge-in their case with written materials and demonstrations of the functionality of the technology. Similar micro-credential [68] training courses could enable people to apply for jobs where in-depth training takes place in the workplace and give them an idea of what lies ahead. The duration of a TC should depend on the complexity of the studied technology, available funding resources, availability of participants and on their readiness to participate in a long-term adult TC and could be shortened if the content is provided in a more intensive manner.

This paper represents a pilot use of the TELIP model outside the educational context. The model was used to examine learning of ET related skills and knowledge through the prism of the IP stages, designing appropriate approaches for initiating and passing the Awareness stage and the Acceptance stage, to estimate the impact of the conducted workshop and TC on learners, and to evaluate their transition between the different IP stages. The TELIP model (Figure 1) allows addressing the appropriate IP factors that determine whether the outcome of the IP stage leads the innovation closer to becoming sustained in the end-user's practices. In this pilot study, these factors were not considered, and this may be one of the reasons why the TC did not yield perfect results. In future work, we plan to consciously exploit the IP factors, in order to ensure better outcomes of future training courses.

In order to start using ETs, including those that could support achieving the Paris Climate Accords targets, a large portion of the population should become ready to start using these ETs, for example, by passing relevant training courses at their workplaces. Wellplanned workshops and TCs that are based on scientific models can save valuable resources, including working time. In addition, such training can be used for discovering challenges, barriers and immaturities of technologies, but also for highlighting opportunities and benefits in certain sectors, and therefore, can be used for accelerating the introduction of ETs in these sectors. The unexpected COVID-19 crisis demonstrated clearly that the necessity for implementing ETs can arise with great urgency. Without proper preparation, the people are unable to meaningfully take full advantage of the opportunities ETs offer. This pilot study represents but one necessary step towards the goal of providing the population rapidly with skills and knowledge that are needed with the ETs that have abruptly become unavoidable.

\section{Limitations and Future Work}

The piloting nature of this study determines the main limitations of the study (small sample sizes in both research phases, its data analysis methods, lack of triangulation). We plan to repeat the study after the end of the COVID-19 restrictions with a larger sample that consists of people from different countries. For collecting data we plan to design and validate a more precise tool that would incorporate both quantitative and qualitative approaches.

We also need to supplement the TELIP model and to develop clearer criteria for identifying the transition between the different IP stages. In this study, we simulated workplace settings of the Acceptance stage. In the future, we plan to exploit the universityindustry collaboration approach and implement real-life workplace settings to TC, in order 
to better represent the context of the potential use of AIER. In addition, it is necessary to examine further whether the innovation adoption sustainability after the simulated IP Acceptance stage is similar to what is achieved through a more natural means (e.g., learning at the workplace).

As the literature offers similar three-stage models (although with less attention on the factors that influence the innovation process during the different stages), tested in different contexts, we consider, in collaboration with relevant science teams, developing the TELIP model to a more generalizable model in the future. This future model could be used as a guiding framework by the representatives of various organizations that currently struggle to prepare themselves for the future.

Author Contributions: Conceptualization: J.L.; Methodology: J.L., T.Õ. and K.L.; Validation: T.Õ. and J.S.M.L.; Formal Analysis: J.L.; Investigation: J.L.; Resources: J.L.; Data Curation: J.L.; WritingOriginal Draft Preparation: J.L., T.Õ., K.L., J.S.M.L.; Writing: J.L., T.Õ., K.L., J.S.M.L.; Visualization: J.L.; Supervision: J.L., T.Õ.; Project Administration: J.L.; Funding Acquisition; T.Õ. All authors have read and agreed to the published version of the manuscript.

Funding: The article processing charges were funded by the School of Educational Sciences, Tallinn University.

Institutional Review Board Statement: Ethical review and approval were waived for this study, due to the following reason. The data collection methods used were low risk methods. The participants were asked for verbal consent and there were no consequences if they did not want to participate in the study. The participants were all legally adults (there were no minors) and they did not belong to any sensitive or vulnerable group. The collected data did not include any sensitive topics, it was used in an anonymized way, and it did not contain any personal or individual-centered sensitive information. The participants were given transparent explication about survey purpose, confidentiality, privacy, and anonymity. There were no potential author or funder conflicts of interest.

Informed Consent Statement: Informed consent was obtained from all subjects involved in the study.

Data Availability Statement: The data that was used in this study is available at: https://bit.ly/ 3FlkHiX (the link leads to Google Drive page, last accessed on 5 October 2021).

Acknowledgments: Project "TU TEE - Tallinn University as a promoter of intelligent lifestyle" (No. 2014-2020.4.01.16-0033) under activity A5 in the Tallinn University Centre of Excellence in Educa-tional Innovation.

Conflicts of Interest: The authors declare no conflict of interest.

\section{References}

1. Rahman, A.A.; Hamid, U.Z.; Thoo, A. Emerging technologies with disruptive effects: A review. PERINTIS Ejournal 2017, 7, 111-128.

2. OECD. Getting Skills Right: Future-Ready Adult Learning Systems; OECD Publishing: Paris, France, 2019. [CrossRef]

3. OECD. Future of Education and Skills 2030. Concept Note; OECD Publishing: Paris, France, 2018.

4. Rotolo, D.; Hicks, D.; Martin, B. What is an emerging technology? Res. Policy 2015, 44, 1827-1843. [CrossRef]

5. Maddox, T. Top 10 Emerging Technologies of 2020: Winners and Losers. Technology Advice. Available online: https://www. techrepublic.com/article/top-10-emerging-technologies-of-2020-winners-and-losers/ (accessed on 5 October 2021).

6. Kurzweil, R. The Singularity Is Near: When Humans Transcend Biology; Viking Adult: New York, NY, USA, 2005.

7. Bugmann, G.; Siegel, M.; Burcin, R. A Role for Robotics in Sustainable Development? In Proceedings of the IEEE Africon 11, Victoria Falls, Zambia, 13-15 September 2011. [CrossRef]

8. Manyika, J.; Chui, M.; Miremadi, M.; Bughin, J.; George, K.; Willmott, P.; Dewhurst, M. Harnessing Automation for a Future That Works; McKinsey Global Institute: San Fransisco, CA, USA, 2017.

9. McKibben, B. Enough: Staying Human in an Engineered Age; Times Books: New York, NY, USA, 2003.

10. Ford, M.R. The Lights in the Tunnel: Automation, Accelerating Technology and the Economy of the Future; Acculant Publishing: Scotts Valley, CA, USA, 2009.

11. Schwartz, J.; Collins, L.; Stocton, H.; Wagner, D.; Walsh, B. The Future of Work. In Rewriting the rules for the Digital Age; Deloitte University Press: New York, NY, USA, 2017.

12. Manyika, J.; Lund, S.; Chui, M.; Bughin, J.; Woetzel, J.; Batra, P.; Ko, R.; Sanghvi, S. Jobs Lost, Jobs Gained: Workforce Transitions in a Time of Automation; McKinsey Global Institute: San Francisco, CA, USA, 2017. 
13. Rios, J.A.; Ling, G.; Pugh, R.; Becker, D.M.; Bacall, A.N. Identifying critical 21st Century for workplace success: A content analysis of job advertisements. Educ. Res. 2020, 49, 80-89. [CrossRef]

14. Voogt, J.; Roblin, N.P. 21st Century Skills. Discussion Paper; University of Twente: Enschede, The Netherlands, 2010.

15. Eagly, A.H.; Chaiken, S.C. Attitude structure and function. In The Handbook of Social Psychology; Gilbert, D.T., Fiske, S.T., Lindzey, G., Eds.; McGraw-Hill: New York, NY, USA, 1998; pp. 269-322.

16. Fazio, R.H.; Roskos-Ewoldsen, D.R. Acting as we feel: When and how attitudes guide behavior. In Persuasion: Psychological Insights and Perspectives; Brock, T.C., Green, M.C., Eds.; Sage Publications: Thousand Oaks, CA, USA, 2005; pp. 41-62.

17. Gnambs, T.; Appel, M. Are robots becoming unpopular? Changes in attitudes towards autonomous robotic systems in Europe. Comput. Hum. Behav. 2019, 93, 53-61. [CrossRef]

18. Dang, J.; Liu, L. Robots are friends as well as foes: Ambivalent attitudes toward mindful and mindless AI robots in the United States and China. Comput. Hum. Behav. 2021, 115, 106612. [CrossRef]

19. Sinclair, J.; Aho, A.-M. Experts on super innovators: Understanding staff adoption of learning management systems. High. Educ. Res. Dev. 2017, 1, 158-172. [CrossRef]

20. Reich-Stiebert, N.; Eyssel, F.; Hohnemann, C. Involve the user! Changing attitudes toward robots by user participation in a robot prototyping process. Comput. Hum. Behav. 2019, 91, 290-296. [CrossRef]

21. Li, D.; Kulasegaram, K.; Hodges, B. Why We Needn't Fear the Machines: Opportunities for Medicine in a Machine Learning World. Acad. Med. 2019, 94, 623-625. [CrossRef]

22. Adner, R.; Levinthal, D.A. The Emergence of Emerging Technologies. Calif. Manag. Rev. 2002, 45, 50-66. [CrossRef]

23. Ziemnowicz, C.; Joseph, A. Schumpeter and Innovation. In Encyclopedia of Creativity, Invention, Innovation and Entrepreneurship, 2nd ed.; Carayannis, E.G., Ed.; Springer: Cham, Switzerland, 2020.

24. Rogers, E.M. Diffusion of Innovations, 5th ed.; Free Press: New York, NY, USA, 2003.

25. Davis, F.D. Technology Acceptance Model for Empirically Testing New End-User Information Systems: Theory and Results. Ph.D. Thesis, Massachusetts Institute of Technology, Massachusetts, CA, USA, 1985.

26. Leoste, J. Adopting and Sustaining Technological Innovations in Teachers' Classroom Practices-The Case of Integrating Educational Robots into Math Classes. Ph.D. Thesis, Tallinn University, Tallinn, Estonia, 2021.

27. Niederhauser, D.S.; Howard, S.K.; Voogt, J.; Agyei, D.D.; Laferriere, T.; Tondeur, J.; Cox, M.J. Sustainability and Scalability in Educational Technology. Technol. Knowl. Learn 2018, 23, 507-523. [CrossRef]

28. Trentin, G.; Alvino, S. Faculty training as a key factor for Web Enhanced Learning sustainability. In Faculty Training for WebEnhanced Learning; Repetto, M., Trentin, G., Eds.; Nova Science Publishers Inc.: Hauppauge, NY, USA, 2011.

29. Davis, F.D.; Bagozzi, R.P.; Warshaw, P.R. User acceptance of computer technology: A comparison of two theoretical models. Manag. Sci. 1989, 35, 982-1003. [CrossRef]

30. DePietro, R.; Wiarda, E.; Fleischer, M. The context for change: Organization, technology and environment. In The Process of Technological Innovation; Tornatzky, L.G., Fleischer, M., Eds.; Lexington Books: Lexington, KY, USA, 1990; pp. 151-175.

31. Venkatesh, V.; Morris, M.G.; Davis, G.B.; Davis, F.D. User acceptance of information technology: Toward a unified view. MIS Q. 2003, 27, 425-478. [CrossRef]

32. Cruz-Jesus, F.; Pinheiro, A.; Oliveira, T. Understanding CRM adoption stages: Empirical analysis building on the TOE framework. Comput. Ind. 2019, 109, 1-13. [CrossRef]

33. Ko, E.; Kim, S.; Kim, M.; Woo, J. Organizational characteristics and the CRM adoption process. J. Bus. Res. 2008, 61, 65-74. [CrossRef]

34. Haberli, C.; Oliveira, T.; Yanaze, M. The adoption stages (Evaluation, Adoption, and Routinisation) of ERP systems with business analytics functionality in the context of farms. Comput. Electron. Agric. 2019, 156, 334-338.

35. Goodarzi, S.H.; Masini, A.; Aflaki, S.; Fahimnia, B. Right Information at the Right Time: Reevaluating the Attitude-Behavior Gap in Environmental Technology Adoption. Int. J. Prod. Econ. 2021, 242, 108278. [CrossRef]

36. Puklavec, B.; Oliveira, T.; Popovic, A. Understanding the determinants of business intelligence system adoption stages: An empirical study of SMEs. Ind. Manag. Data Syst. 2018, 118, 236-261. [CrossRef]

37. Zhu, K.; Kraemer, K.; Xu, S. The process of innovation assimilation by firms in different countries: A technology diffusion perspective on e-business. Manag. Sci. 2006, 52, 1557-1576. [CrossRef]

38. Nguyen, T.; Petersen, T.E. Technology Adoption in Norway: Organizational Assimilation of Big Data. Master's Thesis, Norwegian School of Economics, Bergen, Norway, 2017.

39. Sepasgozar, S.M.; Davis, S.; Loosemore, M.; Bernold, L.E. An investigation of modern building equipment technology adoption in the Australian construction industry. Eng. Constr. Archit. Manag. 2018, 25, 1075-1091. [CrossRef]

40. Brooks-Harris, J.E.; Stock-Ward, S.R. Workshops: Designing and Facilitating Experiential Learning; SAGE Publications: Thousand Oaks, CA, USA, 1999.

41. Belay, H.; Ruairc, B.Ó.; Guérandel, A. Workshops: An important element in medical education. BJPsych Adv. 2019, 25, 7-13. [CrossRef]

42. Tessema, B.S.; Abejehu, S.B. University-Industry Collaboration in Curriculum Development: Analysis of Banking and Finance Graduates' Attributes from Educators and Industries Perspective. Educ. J. 2017, 6, 87-93. [CrossRef] 
43. Matkovic, P.; Tumbas, P.; Sakal, M.; Pavlicevic, V. Curriculum Development Process. Redesign based on University-Industry Cooperation. In Proceedings of the 6th International Conference on Education and New Learning Technologies, Barcelona, Spain, 7-9 July 2014.

44. Khare, M. Employability and higher education in India: The missing links. High. Educ. Future 2014, 1, 39-62. [CrossRef]

45. Sarker, F.; Davis, H.; Tiropanis, T. A review of higher education challenges and data infrastructure responses. In Proceedings of the International Conference for Education Research and Innovation (ICERI2010), Madrid, Spain, 15-17 November 2010.

46. Howard, D.; Eiben, A.E.; Kennedy, D.F.; Mouret, J.-B.; Valencia, P.; Winkler, D. Evolving embodied intelligence from materials to machines. Nat. Mach. Intell. 2019, 1, 12-19. [CrossRef]

47. Hennick, C. Leaps, Bounds, and Backflips. Boston Dynamics. Available online: http://blog.bostondynamics.com/atlas-leapsbounds-and-backflips (accessed on 5 October 2021).

48. Stein, J.P.; Liebold, B.; Ohler, P. Stay back, clever thing! Linking situational control and human uniqueness concerns to the aversion against autonomous technology. Comput. Hum. Behav. 2019, 95, 73-82. [CrossRef]

49. Zhou, S.; Tian, L. Would You Help a Sad Robot? Influence of Robots' Emotional Expressions on Human-Multi-Robot Collaboration. In Proceedings of the 29th IEEE International Conference on Robot and Human Interactive Communication (RO-MAN), Naples, Italy, 31 August-4 September 2020. [CrossRef]

50. Müller-Abdelrazeq, S.L.; Schönefeld, K.; Haberstroh, M.; Hees, F. Interacting with Collaborative Robots-A Study on Attitudes and Acceptance in Industrial Contexts. In Social Robots: Technological, Societal and Ethical Aspects of Human-Robot Interaction; Human-Computer Interaction Series; Korn, O., Ed.; Springer: Cham, Switzerland, 2019. [CrossRef]

51. Oracle, S. Money and Machines: 2021 Global Study; Oracle Corporation: Austin, TX, USA, 2021.

52. Universal Robots. Universal Robot Ur3e. 2021. Available online: https://www.universal-robots.com/products/ur3-robot/ (accessed on 5 October 2021).

53. Leoste, J.; Viik, T.; San Martín López, J.; Kangur, M.; Vunder, V.; Mollard, Y.; Õun, T.; Tammo, H.; Paekivi, K. Robots as my future colleagues: Changing attitudes towards collaborative robots by means of experience-based workshops. In Ludic, Co-design and Tools Supporting Smart Learning Ecosystems and Smart Education. Smart Innovation, Systems and Technologies; Mealha, Ó., Dascalu, M., Di Mascio, T., Eds.; Springer: Singapore, 2021; Volume 249.

54. Huxley, K. Content Analysis, Quantitative. In SAGE Research Methods, Content Analysis, Coding; Atkinson, P., Delamont, S., Cernat, A., Sakshaug, W.W., Williams, R.A., Eds.; Thousand Oaks, CA, USA, 2020.

55. Smith, J.A.; Flowers, P.; Larkin, M. Interpretative Phenomenological Analysis: Theory, Method and Research; SAGE Publications: Thousand Oaks, CA, USA, 2009.

56. Noble, H.; Smith, J. Issues of validity and reliability in qualitative research. Evid.-Based Nurs. 2015, 18, 34-35. [CrossRef]

57. McDonald, N.; Schoenebeck, S.; Forte, A. Reliability and Inter-rater Reliability in Qualitative Research: Norms and Guidelines for CSCW and HCI Practice. Proc. ACM Hum.-Comput. Interact. 2019, 3, 1-23. [CrossRef]

58. Inglis, D. Combating skill fade: Basic life support refresher training in the remote military environment. Resuscitation 2019, 142, E53-E54. [CrossRef]

59. Leoste, J.; Ley, T.T.; Heidmets, M.; Stepanova, J. The Role of Social Practices of Knowledge Appropriation for Sustaining TEL Innovations in the Classroom. In Technology-Enhanced Learning for a Free, Safe, and Sustainable World. EC-TEL 2021; Lecture Notes in Computer Science; De Laet, T., Klemke, R., Alario-Hoyos, C., Hilliger, I., Ortega-Arranz, A., Eds.; Springer: Cham, Switzerland, 2021; Volume 12884.

60. Leoste, J.; Heidmets, M.; Ley, T.T.; Stepanova, J. Classroom Innovation Becoming Sustainable: A Study of Technological Innovation Adoption by Estonian Primary School Teachers. IxDA Interact. Des. Archit. 2020, 47, 144-166.

61. Stephan, M.; Brown, D.; Erickson, R. Talent Acquisition. In Rewriting the Rules for the Digital Age; Deloitte University Press: New York, NY, USA, 2017.

62. Pelster, B.; Johnson, D.; Stempel, J.; van der Vyver, B. Careers and Learning. In Rewriting the Rules for the Digital Age; Deloitte University Press: New York, NY, USA, 2017.

63. OECD. The Human Side of Productivity Uncovering the Role of Skills and Diversity for the Productivity of Firms. Key Highlights; OECD Publishing: Paris, France, 2021.

64. Volini, E.; Schwartz, J.; Eaton, K.; Mallon, D.; Van Durme, Y.; Hauptmann, M.; Poynton, S.; Schoble-Williams, N. The WorkerEmployer Relationship Disrupted; Deloitte Insight: New York, NY, USA, 2021.

65. Irwin, N. Workers are gaining leverage over employers right before our eyes. New York Times, 5 June 2021.

66. Eze, S.C.; Chinedu-Eze, V.C. Examining information and communication technology (ICT) adoption in SMEs: A dynamic capabilities approach. J. Enterp. Inf. Manag. 2018, 31, 338-356.

67. Febrianda, R. Mobile App Technology Adoption in Indonesia's Agricultural Sector. An Analysis of Empirical View from Public R\&D Agency. STI Policy Manag. 2021, 6, 31-40.

68. Clayton, J.; Elliott, R.; Iwata, J. Exploring the use of micro-credentialing and digital badges in learning environments to encourage motivation to learn and achieve. In Rhetoric and Reality: Critical Perspectives on Educational Technology; Hegarty, B., McDonald, J., Loke, S.-K., Eds.; Ascilite: Dunedin, New Zealand, 2014. 